\title{
Interactive comment on "Various aircraft routing options for air traffic simulation in the chemistry-climate model EMAC 2.53: AirTraf 2.0" by Hiroshi Yamashita et al.
}

\section{Anonymous Referee \#2}

Received and published: 3 March 2020

This paper proposes an updated sub-model in the ECHAM Atmospheric Chemistry model for flight trajectory optimisation and is within the scope of the journal (GMD). The algorithm now enables the flight trajectory to be optimised based on various scenarios, which can assist relevant stakeholders and policymakers to evaluate the tradeoff between economic costs and the overall climate impact. Such a tool is expected to become increasingly important as the focus shifts to minimising aviation's overall environmental impact, including both $\mathrm{CO} 2$ and non-CO2 emissions.

While the work is well structured and written, there are several major aspects in the model that were not adequately addressed and must be significantly improved. There-

Printer-friendly version

Discussion paper 
fore, I believe that major revisions are necessary before this paper is accepted for publication.

Major Comments

1) [Page 6, Line 12] What is the rationale for selecting a 20-year time horizon for the average temperature response (ATR20)? Given that a proportion of $\mathrm{CO} 2$ can remain in the atmosphere for over a millennium [Ref.1], the ATR20 can lead to a large underestimation in the $\mathrm{CO} 2$ climate impacts. To overcome this, it is suggested that the authors perform a sensitivity analysis on the reported results by considering the use of different ATR time horizons (i.e. 100 years and 1000 years).

2) [Page 8, Section 2.5.4 and Appendix A] While the methodology selected to model the contrail climate impact was commonly used in previous studies, its limitations should be acknowledged and discussed in the paper. An optimisation algorithm based on the contrail length might be overly simplistic because it does not account for differences in the contrail radiative forcing, lifetime and coverage area:

Firstly, Eq. (A5) assumes that contrails always cool during the day because it has a negative aCCFcontrail and ATR20contrail. However, this is not true as many other studies have shown that contrails can either warm or cool during the day, depending on meteorology (such as ambient cirrus), radiation, and the solar zenith angle.

Secondly, some contrails formed during the day could also have lifetimes of up to 19 hours [Ref.2] and persist through the night, subsequently turning to a warming contrail, but the methodology does not appear to have considered the contrail lifetime. In Eq. (A5), it is also unclear on the conditions/time boundaries which constitutes as day-time and night-time.

Thirdly, the ATR20contrail could also be influenced by contrail spreading and its coverage area. However, Eq. (A5) and "ATR20contrail = aCCFcontrail x PCCdist" does not account for the change in contrail coverage area. Further clarification on these aspects

Printer-friendly version

Discussion paper 
are required.

3) [Page 10, Lines 17 to 19] The results and Figure 2 show that flight trajectories based on the cash operating cost $(\mathrm{COC})$ optimisation and minimum fuel consumption always selects a higher cruising altitude. However, this is very likely due to limitations of BADA 3. According to Nuic et al.[Ref.3], BADA 3 has a tendency to underestimate aircraft fuel consumption at higher altitudes and Mach numbers as the compressibility effect and wave drag are not modelled. While I understand that a more accurate version of BADA (BADA 4) is available, obtaining access to it can be challenging. Despite this, the authors should include more discussion on the effects of BADA 3 on their results, as well as acknowledge the limitations of BADA 3.

4) [Page 11, Lines 9 to 11] "The contrail option shows the minimum contrail distance and decreases ATR20total.... This option allows aircraft to widely detour the potential contrail regions". This sentence requires further clarification: given that the authors mentioned in Page 9 Line 26 that the "ATR20contrail can take positive and negative values, because of the day-time and night-time contrail effects", it should be made clear in the discussion on if the algorithm: (i) actively forms cooling contrails during the day and avoids forming warming contrails during the night; or (ii) minimises the overall contrail length at all times.

\section{Minor Comments}

1) [Page 1, Line 22] Replace "non-volatile black carbon (BC or soot)" with "non-volatile particulate matter such as BC" for correctness in terminology [Ref.4]. This is because black carbon (BC) is a subset of non-volatile particulate matter (nvPM), while the term "soot" includes both nvPM (BC and metallic compounds) and organic compounds.

2) [Page 2, Line 7] The sentence, "The emitted CO2 has a long residence time (a century)", should be corrected. According to Joos et al.1, however, the emitted CO2 can remain in the atmosphere after a millennium.

Printer-friendly version

Discussion paper 
3) [Page 3, Line 15] Remove "the" from this sentence "the today's aircraft routing focuses on the minimum economic cost".

4) [Page 8, Line 22] There appears to be inconsistencies in the acronyms: Ctime and Cfuel was used in line 22. However, ct and cf are used in Eq. (6). This can confuse future readers.

5) [Section 2.5.7] Please acknowledge the large uncertainties in the global temperature response, especially from contrails (ATR20contrail) due to uncertainties in the contrail efficacy[Ref.5,6].

6) [Section 4: Discussion] The authors should highlight that these results (climate benefits) is likely an upper limit, because airspace congestion and air traffic management could minimise the flexibility for flights to perform these trajectory optimisations.

7) [Eq. (5) and Table 1] Consider using different notations for the mass fuel flow rate (fref), as this is similar to the objective function (f) and can lead to confusion.

8) $[$ Appendix A, Eq. (A5)] aCCFcontrail $=\ldots$., if Potcov $\geq 0$ : should this be $>0$ instead? Similarly, aCCFcontrail $=0$, if Potcov $<0$ : should this be $\leq 0$ instead?

\section{References}

1. Joos F, Roth R, Fuglestvedt JS, Peters GP, Enting IG, von Bloh W, Brovkin V, Burke EJ, Eby M, Edwards NR, Friedrich T, Frölicher TL, Halloran PR, Holden PB, Jones C, Kleinen T, Mackenzie FT, Matsumoto K, Meinshausen M, et al. Carbon dioxide and climate impulse response functions for the computation of greenhouse gas metrics: a multi-model analysis. Atmos Chem Phys. 2013;13(5):2793-2825. doi:10.5194/acp-132793-2013

2. Haywood JM, Allan RP, Bornemann J, Forster PM, Francis PN, Milton S, Rädel G, Rap A, Shine KP, Thorpe R. A case study of the radiative forcing of persistent contrails evolving into contrailâĂŘinduced cirrus. J Geophys Res Atmos. 2009;114(D24201). doi:doi:10.1029/2009JD012650

Printer-friendly version

Discussion paper 
3. Nuic A, Poles D, Mouillet V. BADA: An advanced aircraft performance model for present and future ATM systems. Int J Adapt Control Signal Process. 2010;24(10):850866. doi:10.1002/acs.1176

4. Petzold A, Ogren JA, Fiebig M, Laj P, Li S-M, Baltensperger U, Holzer-Popp T, Kinne S, Pappalardo G, Sugimoto N. Recommendations for reporting" black carbon" measurements. Atmos Chem Phys. 2013;13(16):8365-8379.

5. Hansen J, Sato M, Ruedy R, Nazarenko L, Lacis A, Schmidt GA, Russell G, Aleinov I, Bauer M, Bauer S, Bell N, Cairns B, Canuto V, Chandler M, Cheng Y, Genio A Del, Faluvegi G, Fleming E, Friend A, et al. Efficacy of climate forcings. J Geophys Res. 2005;110(D18):D18104. doi:10.1029/2005JD005776

6. Ponater M, Marquart S, Sausen R, Schumann U. On contrail climate sensitivity. Geophys Res Lett. 2005;32(10).

Interactive comment on Geosci. Model Dev. Discuss., https://doi.org/10.5194/gmd-2019-331, 2019. 